\title{
EU research plan fails to charm critics
}

[MUNICH] Draft proposals for the European Union (EU)'s next five-year research programme, published in Brussels last week, suggest that hopes for a greater concentration of EU research funds on fewer research topics may not materialize.

Furthermore, the proposals in the second working document on the EU's fifth Framework research programme (FP5), covering 1999 to 2003, reveal a complex management structure that many fear may be unworkable.

But EU officials defend the proposals as linking FP5 directly to the economic and social goals of member states. Furthermore, the proposals suggest that basic research could form up to 10 per cent of the overall budget, likely to be just over ECU13 billion ( $\$ 15$ billion). This is significantly more than in previous research programmes.

The proposals were adopted by the full commission last week after several weeks' delay. They confirm the commission's intention to divide research into six programmes, as envisaged in the first working paper published last July (see Nature 382, 194; 1996), rather than the nineteen included in the current framework programme, FP4.

\section{Themes within themes}

But the six programmes are very broad, and are broken down into at least as many categories as in FP4. These would be linked by a complex management system involving considerable coordination and consultation.

Three of the main programmes are described as 'thematic', focusing on life sciences and the ecosystem, the 'user-friendly information society', and competitive and sustainable growth. Each thematic programme is in turn broken down into $16^{\circ} \mathrm{key}$ actions', corresponding to specific social or economic priorities for the EU.

According to Jack Metthey, a member of the cabinet of the research commissioner, Edith Cresson, with responsibility for

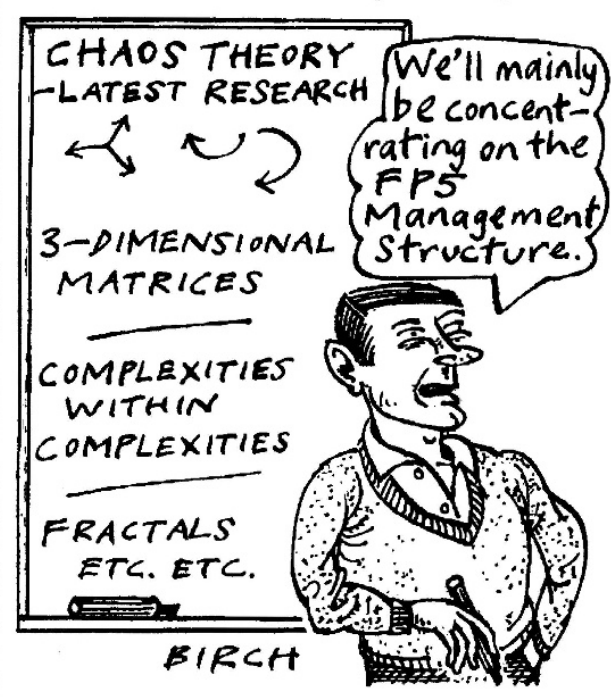

research policy, the commission sees the key actions as extending the task force idea launched two years ago to coordinate all EU research activities on a specific theme.

Each thematic programme also includes support for developing relevant generic technologies and basic research, as well as for large-scale infrastructures.

Three 'horizontal programmes' would have their own budgets but also feed into the thematic programmes, using a matrix management system. They cover international cooperation, innovation and the participation of small- and medium-sized enterprises, and improving human potential. Three other programmes will be carried out by the EU's Joint Research Centres and under the Euratom programme.

Observers in Brussels are concerned about the broad content of the proposals, and sceptical about how the proposed management system would work in practice.

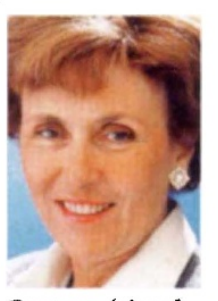

effective system?

In response, Metthey says that the breadth of the research activities will be reduced when a formal proposal is submitted to the European Council of Ministers which represents the member states of the EU - and the European Parliament at the end of next month.

"This is a reflection document, not a formal commission proposal," he says, adding that the commission will respond to the reactions of industry interest groups and representatives of the basic research community, as well as to the recommendations of a fiveyear independent assessment of EU research activities, due out this week.

\section{More management, more flexibility?}

Metthey insists the proposal for FP5 "will definitely not grow beyond the six programmes, and it is our firm intention to reduce the number of key actions in our formal proposal". But achieving this may not be easy. Although all member states agree that the number of actions must be reduced, most are likely to defend those in which they have strong interests - and the programme needs the unanimous support of the Council of Ministers.

Metthey also denies that the planned management system is excessively complex, emphasizing its flexibility. Only three-fifths of each programme's budget will initially be fixed, enabling the commission to react quickly to new developments or emergencies, such as the scare over bovine spongiform encephalopathy (BSE).

Indeed, he suggests, the decision-making process will be much simpler and quicker, as the number of programme committees - made up of senior officials from member states - will be reduced in line with the number of programmes. Further, the adoption and implementation of FP5 requires twelve decisions, half the number for FP4.

And the emphasis on coordination between FP5 and other EU initiatives, as well as national research programmes and research programmes of non-EU European laboratories such as CERN, the European Particle Physics Laboratory and EMBL, the European Molecular Biology Laboratory, can only increase efficiency, he adds. The budget of the Training and Mobility of Researchers Programme, which includes a high proportion of basic research projects and networks, is expected to be doubled.

\section{Larger funds for basic research}

The document does not detail the amount of money the commission is likely to propose for FP5. But this is expected to be just slightly higher than the ECU13 billion spent on FP4. The basic research component, which, Metthey says, "is being regarded very sympathetically", could be about 10 per cent.

Richard Brook, head of the UK Engineering and Physical Sciences Research Council, says that, until the figures are added, "it is hard to see how the commission will translate its aspirations [for the concentration of programmes] into reality". It needs to clarify what it intends to leave out and how much money it would give to each action, he says.

$\mathrm{He}$ sees the proposed structure of FP5 with its six programmes as "reclassifying the family tree" without significantly changing the contents. And he fears that the flexibility theoretically allowed by the proposed matrix-style management system could be offset by the frictions likely to be generated by continuous debate.

Jan Borgmann, head of the EU's advisory body, the European Science and Technology Assembly, shares this concern. "The commission will have to do considerably more homework to explain how it thinks it could work in practice," he says.

Pierre Papon, director of the Observatoire des Sciences et Technologies in Paris, views the proposed broad spectrum of themes as unrealistic. "You can find almost everything" in the three thematic programmes, he says. But he approves the individual proposed key actions. Although there are too many, he says, they introduce some new ideas in line with EU general policy.

And Edith Cresson remains optimistic about the proposed system. She said in a speech last week that the management structure "will help to make the framework programme a simple and effective instrument capable of reacting rapidly to situations and needs".
Alison Abbott 